\title{
Evaluation of Complete Blood Count Parameters to Predict Ovarian Torsion in Women with Adnexal Mass
}

\author{
Ahter T. TAYYAR ${ }^{1}$, Enis ÖZKAYA ${ }^{1}$, Çiğdem ABi̇de YAYLA ${ }^{1}$, M. Baki ŞENTÜRK ${ }^{1}$, Selçuk SELÇUK ${ }^{1}$, Mesut POLAT ${ }^{1}$ \\ Cevat Rıfat CÜNDÜBEY', Mehmet TAYYAR ${ }^{1}$
}

Istanbul, Turkey

\begin{abstract}
OBJECTIVE: The aim of this study was to evaluate complete blood count parameters to predict ovarian torsion in cases presented with ovarian mass.

STUDY DESIGN: Pre-operative demographic data and complete blood count parameters of 72 patients, who were operated on preliminary adnexal torsion and diagnosed as adnexal torsion with a benign ovarian cyst (Study group) were retrospectively compared with those of 77 patients who were operated with an indication of persistent benign ovarian cysts without torsion (control group) at Zeynep Kamil Women and Children's Health Training and Research Hospital and Department of Obstetrics \& Gynecology at Erciyes University Medical Faculty between 2011 and 2015. Complete blood count parameters were utilized to predict ovarian torsion cases.
\end{abstract}

RESULT: Neutrophil ( $A \cup C=792, p=<0.001$ ), white blood cell ( $A \cup C=787, p=<0.001$ ) counts and neutrophil/lymphocyte ratio ( $A \cup C=770, p=<0.001$ ) were significant predictors for adnexal torsion. Optimal cut off value for white blood cell, neutrophil count and neutrophil/lymphocyte ratio were $8.3 \times 103(72 \%$ sensitivity, 73\% specificity), 5.5x103 (73\% sensitivity, 76\% specificity), 2.9 (73\% sensitivity, 79\% specificity) respectively.

CONCLUSION: Among all the parameters white blood cell count, neutrophil/lymphocyte and neutrophil count were the most powerful predictors for real adnexal torsion cases. Simple blood count parameters detailed evaluation may help clinicians to confirm or rule out adnexal torsion in cases presented with ovarian cyst and adnexal mass.

Keywords: Adnexal torsion, White blood cell count, Inflammation, Necrosis

Gynecol Obstet Reprod Med 2017;23(2):89-93

\section{Introduction}

A complete or partial rotation of the ovary, adnexal torsion, is one of the most common gynecologic emergencies and may affect females of all ages and may result in ischemia and necrosis of the ovary $(1,2)$. An early diagnosis and intervention are mandatory to preserve ovarian function and to prevent associ-

${ }^{1}$ Department of Obstetrics and Gynecology of Zeynep Kamil Women and
Children's Health Training and Research Hospital, Istanbul
Address of Correspondence: Enis Özkaya
Department of Obstetrics and
Gynecology, Zeynep Kamil Training and
Research Hospital Istanbul, Turkey
enozkaya1979@gmail.com

\begin{tabular}{|c|c|}
\hline \multicolumn{2}{|c|}{ Access this article online } \\
\hline 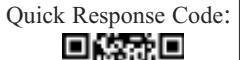 & Website: www.gorm.com.tr \\
\hline 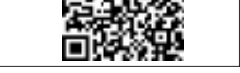 & DOI:10.201613/GORM.2016.655 \\
\hline
\end{tabular}

How to cite this article: Tayyar AT. Özkaya E. Abide Yayla C. Sentürk MB. Selçuk S.Polat M. et al. Evaluation of Complete Blood Count Parameters to Predict Ovarian Torsion in Women with Adnexal Mass. Gynecol Obstet Reprod Med 2017;23(2):89-93 ated morbidity. An early diagnosis can be made according to the results of combination of symptoms, signs and ultrasound findings. However, in majority of the cases certain diagnosis is not that much easy due to the nonspecific symptoms. Ultrasound scans have limited value with a sensitivity of 46 to $75 \%$ in the diagnosis of ovarian torsion $(3,4)$. There is no welldefined serum biochemical marker having role in determining adnexal torsion. Adnexal torsion was showed to result in inflammatory response determined in histological sections (5). White blood cell count is a potential indicator for inflammation in the body. The five types of white blood cells are monocytes, lymphocytes, basophils, eosinophils and neutrophils. Studies have concluded that there is an increase in white blood cell counts in adnexal torsion cases (6). Some studies assessed the predictive value of hematologic inflammatory markers including neutrophil/lymphocyte ratio, red cell distribution width and platelet distribution width, to predict some malignancies or other pathologies resulted in inflammatory response (7). Neutrophil/lymphocyte ratio has shown to be elevated in response to stress-related systemic inflammation (8).

The aim of this study was to evaluate complete blood count parameters to predict ovarian torsion in cases presented with ovarian mass. 


\section{Material and method}

Study protocol: In this retrospective study, 156 women underwent surgical exploration due to adnexal mass. Study group consisted of women suspected to have ovarian torsion $(n=72)$, where as there were 77 subjects with persistent ovarian mass scheduled for ovarian cystectomy. Institutional review board approved the study protocol. A detailed medical history was obtained, and then all subjects underwent a complete physical examination. A complete blood count was assessed in each case, transvaginal and/or pelvic ultrasonography was performed to all patients with suspected ovarian cysts, by the same experienced gynecologist. Ovarian torsion was suspected in cases with acute intermittent lower abdominal pain, accompanied by nausea and vomiting and if the ultrasound examination revealed adnexal pathology. Exclusion criteria were any systemic disease including cardiovascular, endocrinological, metabolic, inflammatory and autoimmune disorders and cases confirmed to have appendicitis. After laparoscopic surgical exploration, seven cases with non-gynecological pathology were excluded from the study. In majority of the cases ovarian-conserving surgery or oophorectomy was performed, depending on the patient's age, nature of the cyst or adnexal pathology and the degree of necrosis on the ovary. After the operation, 72 women confirmed to have adnexal torsion. The patients' demographic features, complete blood count parameters such as hematocrit, hemoglobin concentration, lymphocyte, platelet, and neutrophil counts were recorded and analyzed to predict cases with adnexal torsion.

Outcomes: The primary outcome was a correct diagnosis of torsion using one or more of the hematologic inflammatory parameters among females with ovarian cysts and lower abdominal pain.

Laboratory methods: A complete blood count was taken in an EDTA blood tube, stored at $4^{\circ} \mathrm{C}$, centrifuged for $10 \mathrm{~min}$ at $4000 \mathrm{rpm}$, and the plasma was separated. The red cell distribution width, platelet cell distribution width and neutrophil/lymphocyte ratio were measured using a Beckman Coulter Automated CBC Analyzer (Beckman Coulter Inc., Fullerton, Miami, FL).

Statistics: All the data was analyzed by SPSS Version 15 (IBM, Chicago, IL). The values are expressed as percentages or mean SD. Continuous variables were compared by independent samples t test or Mann Whitney-U test. The prognostic performance of the hematologic inflammatory variables was measured with receiver operating characteristic curves. The sensitivity, specificity, positive likelihood ratio and negative likelihood ratio were calculated using different cut-off values. A value of $\mathrm{p}$ $<0.05$ was considered significant. groups

\section{Results}

Study group consisted 72 patients with laparoscopically confirmed ovarian torsion (Study group) where as 77 women accepted to be the control group, which consisted of cases without adnexal torsion determined by laparoscopy. Comparison of some demographic and clinical parameters between groups revealed significant differences with regard to age (37 vs. 27), gravidity (2.4 vs. 1.3$)$, parity (1.8 vs. 1.04$)$ and number of alive children (1.8 vs. 1.04$)$ and miscarriage $(0.5$ vs. 0.2). Comparison of clinical parameters was shown in Table 1. Neutrophil (AUC=792, $\mathrm{p}=<0.001$ ), white blood cell

Table 1: Comparison some complete blood count parameters between

\begin{tabular}{|c|c|c|c|c|c|}
\hline & Groups & $n$ & Mean & $\begin{array}{l}\text { Std. } \\
\text { Deviation }\end{array}$ & $\begin{array}{l}\text { Std. Error } \\
\text { Mean }\end{array}$ \\
\hline \multirow{2}{*}{$\begin{array}{l}\text { White blood cell count } \\
\left(10^{3} / \mathrm{mm}^{3}\right)\end{array}$} & Control & 77 & 7.2 & 2.1 & \\
\hline & Torsioned & 72 & 10.3 & 3.4 & $<0.001$ \\
\hline \multirow{2}{*}{$\begin{array}{l}\text { \# of Neutrophil } \\
\left(10^{3} / \mathrm{mm}^{3}\right)\end{array}$} & Control & 77 & 4.6 & 1.9 & \\
\hline & Torsioned & 72 & 7.9 & 3.6 & $<0.001$ \\
\hline \multirow{2}{*}{$\begin{array}{l}\text { \# of Basophil } \\
\left(10^{3} / \mathrm{mm}^{3}\right)\end{array}$} & Control & 77 & 0.04 & 0.03 & \\
\hline & Torsioned & 72 & 0.05 & 0.04 & 0.342 \\
\hline \multirow{2}{*}{$\begin{array}{l}\text { \# of Eosinophil } \\
\left(10^{3} / \mathrm{mm}^{3}\right)\end{array}$} & Control & 77 & 0.1 & 0.06 & \\
\hline & Torsioned & 72 & 0.07 & 0.09 & 0.037 \\
\hline \multirow{2}{*}{$\begin{array}{l}\text { \# of Lymphocyte } \\
\left(10^{3} / \mathrm{mm}^{3}\right)\end{array}$} & Control & 77 & 1.9 & 0.6 & \\
\hline & Torsioned & 72 & 2.1 & 3.7 & 0.861 \\
\hline \multirow{2}{*}{$\begin{array}{l}\text { \# of Monocyte } \\
\left(10^{3} / \mathrm{mm}^{3}\right)\end{array}$} & Control & 77 & 0.4 & 0.1 & \\
\hline & Torsioned & 72 & 0.5 & 0.2 & 0.232 \\
\hline \multirow{2}{*}{$\begin{array}{l}\text { Red blood cell count } \\
\left(10^{3} / \mathrm{mm}^{3}\right)\end{array}$} & Control & 77 & 4.3 & 0.3 & \\
\hline & Torsioned & 72 & 4.1 & 0.5 & 0.008 \\
\hline \multirow{2}{*}{$\begin{array}{l}\text { Hemoglobin } \\
\text { (gr/dL }\end{array}$} & Control & 77 & 12.2 & 1.7 & \\
\hline & Torsioned & 72 & 11.4 & 1.5 & 0.062 \\
\hline \multirow[t]{2}{*}{ Hematocrit (\%) } & Control & 77 & 37.1 & 4.8 & \\
\hline & Torsioned & 72 & 34.5 & 4.3 & 0.033 \\
\hline \multirow{2}{*}{$\begin{array}{l}\text { Mean corpuscular } \\
\text { volume }(\%)\end{array}$} & Control & 77 & 84.9 & 8.5 & \\
\hline & Torsioned & 72 & 85.2 & 5.3 & 0.920 \\
\hline \multirow{2}{*}{$\begin{array}{l}\text { Mean corpuscular } \\
\text { hemoglobin }\end{array}$} & Control & 77 & 27.9 & 3.1 & \\
\hline & Torsioned & 72 & 28.1 & 2.1 & 0.830 \\
\hline \multirow{2}{*}{$\begin{array}{l}\text { Mean corpuscular hemo- } \\
\text { globin concentration }\end{array}$} & Control & 77 & 32.8 & 1.1 & \\
\hline & Torsioned & 72 & 33.1 & 1.1 & 0.647 \\
\hline \multirow[t]{2}{*}{ Red cell distribution width } & Control & 77 & 15.2 & 2.5 & \\
\hline & Torsioned & 72 & 14.5 & 2.7 & 0.320 \\
\hline \multirow[t]{2}{*}{ Platelet \#(mm²) } & Control & 77 & 295000 & 103345.2 & \\
\hline & Torsioned & 72 & 130205 & 172956.4 & $<0.001$ \\
\hline \multirow[t]{2}{*}{ Mean platelet volume (fl) } & Control & 77 & 8.8 & 1.2 & \\
\hline & Torsioned & 72 & 8.3 & 1.1 & 0.154 \\
\hline \multirow{2}{*}{$\begin{array}{l}\text { Neutrophil/lymphocyte } \\
\text { ratio }\end{array}$} & Control & 77 & 2.8 & 2.2 & \\
\hline & Torsioned & 72 & 6.3 & 4.6 & $<0.001$ \\
\hline \multirow[t]{2}{*}{ Platelet/lymphocyte ratio } & Control & 77 & 170.9 & 110.9 & \\
\hline & Torsioned & 72 & 104.2 & 156.7 & 0.003 \\
\hline
\end{tabular}


(AUC $=787, \mathrm{P}=<0.001)$ counts and neutrophil/lymphocyte ratio $(\mathrm{AUC}=770, \mathrm{p}=<0.001$ ) were significant predictors for adnexal torsion (Figure 1). Optimal cut off value for white blood cell, neutrophil count and neutrophil/lymphocyte ratio were $8.3 \times 103$ (72\% sensitivity, $73 \%$ specificity), 5.5x103 (73 $\%$ sensitivity, $76 \%$ specificity), 2.9 (73\% sensitivity, 79\% specificity) respectively. Odds ratios for $\mathrm{WBC}>8.3 \times 103$, number of neutrophil $>5.5 \times 103$, neutrophil/lymphocyte $>2.9$ for ovarian torsion were 6.6 (95\% CI, 3.2-13.5), 7.5 (95\% CI, 3.6-15.5), 9.3 (95\% CI, 4.4-19.6) respectively.

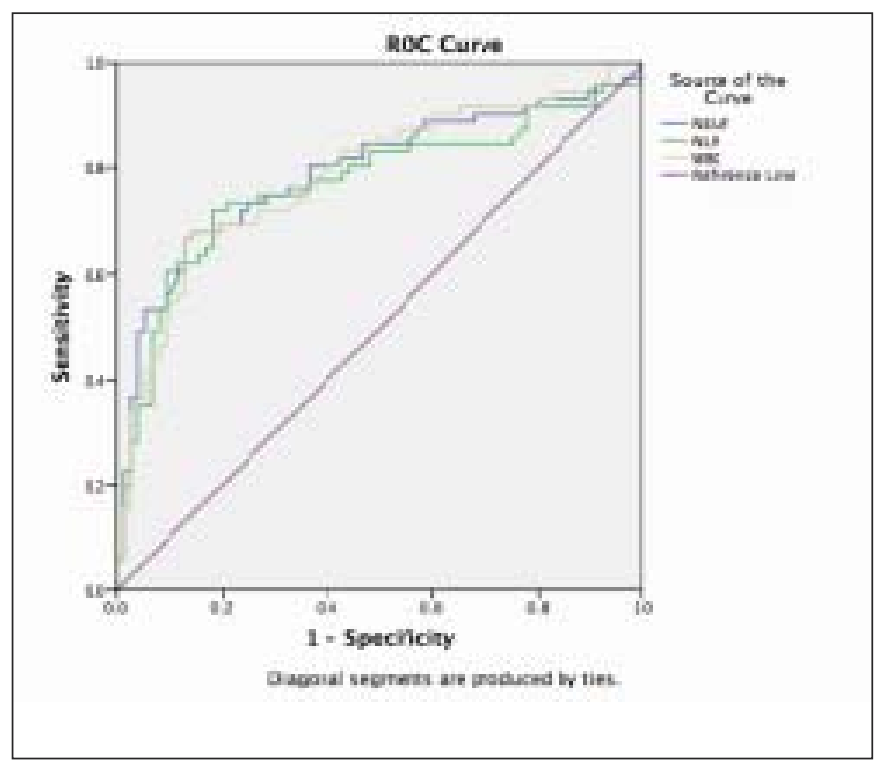

Figure 1: ROC curve of neutrophil, white blood cell count and neutrophil/lymphocyte ratio to predict torsioned adnexa.

\section{Discussion}

In this study, we tried to predict ovarian torsion among cases underwent laparoscopic surgery due to adnexal mass by some complete blood count parameters including hematocrit, hemoglobin concentration, lymphocyte, platelet, neutrophil counts, neutrophil/lymphocyte and platelet/lymphocyte ratios. Our data analysis revealed significant associations between white blood cell, neutrophil count and neutrophil/lymphocyte with ovarian torsion. In a recently published study on this issue, authors concluded that the neutrophil/lymphocyte ratio might have diagnostic and prognostic value in determining torsioned ovarian cysts (9). In their study, authors also showed RDW to be significantly increased in cases with adnexal torsion, consistent with their result we found lower RDW values in cases with torsioned adnexa but the difference did not reach statistical significance in our study, may be due to the small sample size.

Ovarian torsion is seen in $2.7 \%$ of all gynecologic emergencies (1). It results from adnexal rotation around the infundibulopelvic ligament and the uteroovarian ligament, and obstruction of the arteria and vena ovarica. Ovarian failure may develop in cases with delayed intervention due to the ovarian necrosis (10).
In majority of the cases right adnexa become torsionedz (11). Clinical and medical assessment, symptoms, physical examination and ultrasound evaluation give some clue for the diagnosis of ovarian torsion. However, the diagnosis of ovarian torsion can be challenging due to the nonspecific symptoms and low sensitivities of the diagnostic tools. A certain diagnosis can be made only at surgical exploration by seeing the twisted ovarian stalk. Ultrasonography is the most frequently used screening method for the diagnosis of adnexal torsion. Ultrasonographic findings of adnexal torsion include abnormal ovary positions, ovarian expansion with fluid retention, ovarian or adnexal cysts and free liquid in a cul-de-sac. Doppler ultrasound assessment has some value for the diagnosis of ovarian torsion. However, in the study by Oltmann et al., in $46 \%$ of children with ovarian torsion, the preoperative ultrasound findings were interpreted as normal (12). In another study it was claimed that, despite the existence of torsion in the ovaries, Doppler ultrasonography provides normal results in $60 \%$ of the cases due to the dual blood supply nature (13). The absence of any specific clinical findings could cause diagnostic issues and poor preoperative accuracy (14). Therefore, due to the necessity of experienced staff for Doppler and clinical assessment for the diagnosis and minimally invasive approach, some difficulties can be experienced during nightshifts. So cheap and easily available tests are needed to make certain diagnosis and prompt intervention especially during nightshifts. Timely diagnosis and minimally invasive approach are particularly important for fertile young patients. Some serum markers have been proposed to be used for ovarian torsion diagnosis including interleukin-6 (IL-6), tumor necrosis factor-alpha, interleukin-8, and E-selectin, authors concluded that the IL- 6 levels might assist in the prompt diagnosis of ovarian torsion and allow a timely surgical intervention (15). However, IL-6 does not seem to be useful as it is expensive and cannot easily be measured. So complete blood count parameters were analyzed to predict various types of disorders result in inflammatory response (16-20). Generally it is expected to see some infarcts in ovarian tissue of cases with torsioned adnexa. There are some data on this issue indicating that the higher peripheral leukocyte and neutrophil counts, but not lymphocyte counts may be associated with larger tissue infarct volumes (21).

Another surgical emergency that result in inflammatory response, acute appendicitis, is not uncommon during pregnancy but can be difficult to diagnose. A previous study evaluated the neutrophil/lymphocyte and platelet/lymphocyte ratios adjunct to conventional diagnostic indicators of the disease to diagnose acute appendicitis during pregnancy. And also mean white blood cell counts and CRP levels were shown to be higher in women with proven acute appendicitis than in those of control groups. Study proposed that in addition to routine diagnostic methods, neutrophil/lymphocyte and platelet/lymphocyte ratios increased the accuracy of the diag- 
nosis of acute appendicitis in pregnant women (22). Due to this data we excluded the cases with appendicitis diagnosed during surgical exploration.

Recently, neutrophil/lymphocyte has been widely analyzed to determine the degree of inflammation in some systemic disorders including cardiovascular diseases, malignancy, diabetes mellitus, hypertension and auto inflammatory diseases (23). Neutrophil/lymphocyte ratio has been reported to be a positive marker for a series of diseases including endometriosis, endometrial cancer, pelvic inflammatory disease, preterm birth, ovarian cancer, cervical cancer, gestational trophoblastic disease, ovarian hyperstimulation syndrome (OHSS), endometrial hyperplasia, gestational diabetes, preeclampsia and uterine sarcoma (24). According to our literature search, there are few studies published that utilized these markers for ovarian torsion diagnosis, authors claimed that low systemic inflammatory response due to ischemia was found to result in neutrophilia and the relative lymphopenia by cortisol-induced stress response (25). Consistent with our study, study by Yilmaz et al showed that the neutrophil count of the patients with a torsioned ovarian cyst increased significantly compared with that of the control group, but the lymphocyte count decreased, in their study authors concluded that the neutrophil/lymphocyte might have diagnostic and prognostic value in determining torsioned ovarian cysts (9).

Retrospective nature and the small sample size are the major disadvantages of this study.

In conclusion, among all the parameters white blood cell, neutrophil count and neutrophil/lymphocyte were the most powerful predictors for real adnexal torsion cases. A simple blood count parameters detailed evaluation may help clinicians to confirm or rule out adnexal torsion in cases presented with ovarian cyst and adnexal mass.

\section{References}

1. McWilliams GD, Hill MJ, Dietrich CS $3^{\text {rd }}$. Gynecologic emergencies. Surg Clin North Am 2008;88(2):265-83.

2. Celik H, Tosun M, Kefeli M, Bilge MC, Kökçü A, Altunsoy S. et al. Torsion of a Normal Ovary and Torsion of a Ovarian Tumor Two Different Unusual Cases. Gynecol Obstet Reprod Med 2008;14(3):208-10.

3. Mashiach R, Melamed N, Gilad N, Ben-Shitrit G, Meizner I. Sonographic diagnosis of ovarian torsion: accuracy and predictive factors. J Ultrasound Med 2011;30(9):1205-10.

4. Wilkinson C, Sanderson A. Adnexal torsion a multimodality imaging review. Clinical Radiology 2012;(5):476-83.

5. Fujiwara K, Moriya T, Mikami Y, Hiratsuka J, Sawada S, Imajo Y et al. Significant increases in serum CA125 and CA19-9 following torsion from an adenofibroma of the ovary: a case report. Jpn J Clin Oncol 1994; 24(2):116-9.

6. Tobiume T, Shiota M, Umemoto M, Kotani Y, Hoshiai H.
Predictive factors for ovarian necrosis in torsion of ovarian tumor. Tohoku J Exp Med 2011;225(3):211-4.

7. Templeton AJ, McNamara MG, Šeruga B, Vera-Badillo FE, Aneja P, Ocaña A. et al. Prognostic role of neutrophilto-lymphocyte ratio in solid tumors: a systematic review and meta-analysis. J Natl Cancer Inst 2014;106(6): dju124.

8. Bhat T, Teli S, Rijal J, Bhat H, Raza M, Khoueiry, et al. Neutrophil to lymphocyte ratio and cardiovascular diseases: a review. Expert Review of Cardiovascular Therapy 2013;11(1):55-9.

9. Yilmaz M, Cimilli G, Saritemur M, Demircan F, Isaoglu U, Kisaoglu A. et al. Diagnostic Accuracy of Neutrophil/ Lymphocyte Ratio, Red Cell Distribution Width and Platelet Distribution Width in Ovarian Torsion. J Obstet Gynaecol 2016;36(2):218-22.

10. Schrager J, Robles G, Platz T. Isolated fallopian tube torsion: a rare entity in a premenarcheal female. The American Surgeon 2012;78(2):118-9.

11. Huchon C, Fauconnier A. Adnexal torsion: a literature review. Eur J Obstet Gynecol Reprod Biol 2010;150(1):812.

12. Oltmann SC, Fischer A, Barber R, Huang R, Hicks B, Garcia N. Cannot exclude torsion a 15-year review. J Pediatr Surg 2009;44(6):1212-6.

13. Servaes S, Zurakowski D, Laufer MR, Feins N, Chow JS. Sonographic findings of ovarian torsion in children. Pediatr Radiol 2007;37(5):446-51.

14. Weizig Z, Perron J, Grubb D, Debra M, Daniel R. Conservative management of adnexal torsion. Am J Obstet Gynecol 1993;168 (6 Pt 1):1791-5.

15. Daponte A, Pournaras S, Hadjichristodoulou C, Lialios G, Kallitsaris A, Maniatis AN. et al. Novel serum inflammatory markers in patients with adnexal mass who had surgery for ovarian torsion. Fertil Steril 2006;85 (5):1469-72

16. Felker GM, Allen LA, Pocock SJ, Shaw LK, McMurray JJ, Pfeffer MA, et al. Red cell distribution width as a novel prognostic marker in heart failure: data from the CHARM Program and the Duke Databank. J Am Coll Cardiol 2007;50(1):40-7

17. Ku NS, Kim HW, Oh HJ, Kim YC, Kim MH, Song JE, et al. Red blood cell distribution width is an independent predictor of mortality in patients with gram-negative bacteremia. Shock 2012; 38(2):123-7.

18. Senol K, Saylam B, Kocaay F, Tez M. Red cell distribution width as a predictor of mortality in acute pancreatitis. Am J Emerg Med 2013;31(4):687-9

19. Sadaka F, O'Brien J, Prakash S. Red cell distribution width and outcome in patients with septic shock. J Intensive Care Med 2013;28(5):307-13.

20. Magri CJ, Fava S. Red blood cell distribution width and diabetes associated complications. Diabetes Metab Syndr 
$2014 ; 8(1): 13-7$

21. Buck BH, Liebeskind DS, Saver JL, Bang OY, Yun SW, Starkman S, et al. Early neutrophilia is associated with volume of ischemic tissue in acute stroke. Stroke 2008; 39(2):355-60.

22. Yazar FM, Bakacak M, Emre A, Urfalıglu A, Serin S, Cengiz E. et al. Predictive role of neutrophil-to-lymphocyte and platelet-to-lymphocyte ratios for diagnosis of acute appendicitis during pregnancy. Kaohsiung J Med Sci 2015;31(11):591-6.

23. Imtiaz F, Shafique K, Mirza SS, Ayoob Z, Vart P, Rao S.
Neutrophil lymphocyte ratio as a measure of systemic inflammation in prevalent chronic diseases in Asian population. Int Arch Med 2012;26;5(1):2.

24. Ercan Ö, Köstü B, Bakacak M, Coşkun B, Tohma A, Mavigök E. Neutrophil to Lymphocyte ratio in the diagnosis of adnexal torsion. Int J Clin Exp Med 2015;8(9): 16095-100.

25. Tamhane UU, Aneja S, Montgomery D, Rogers EK, Eagle KA, Gurm HS. Association between admission neutrophil to lymphocyte ratio and outcomes in patients with acute coronary syndrome. Am J Cardiol 2008 Sep 15;102(6): $653-7$ 